\title{
An adjusted and time-saving method to measure collateral ventilation with Chartis
}

\author{
T. David Koster $\mathbb{D}^{1}$, Karin Klooster ${ }^{1}$, Hallie McNamara ${ }^{2}$, Narinder S. Shargill ${ }^{2}$, Sri Radhakrishnan ${ }^{2}$, \\ Ryan Olivera ${ }^{2}$ and Dirk-Jan Slebos (D) $^{1}$
}

${ }^{1}$ Dept of Pulmonary Diseases, University of Groningen, University Medical Center Groningen, Groningen, The Netherlands. ${ }^{2}$ Pulmonx Corporation, Redwood City, CA, USA.

Corresponding author: T. Koster (t.d.koster@umcg.nl)

Shareable abstract (@ERSpublications)

The volume trend for the previous $20 \mathrm{~s}$ (VT20) is an adjusted method of the Chartis measurement. This feature helps to interpret the Chartis measurement more easily and it effectively shortens the Chartis assessment time, especially in cases with low flow. https://bit.ly/3wlClxv

Cite this article as: Koster TD, Klooster $\mathrm{K}, \mathrm{McNamara} \mathrm{H}$, et al. An adjusted and time-saving method to measure collateral ventilation with Chartis. ERJ Open Res 2021; 7: 00191-2021 [DOI: 10.1183/ 23120541.00191-2021].

Copyright (The authors 2021

This version is distributed under the terms of the Creative Commons Attribution NonCommercial Licence 4.0. For commercial reproduction rights and permissions contact permissions@ersnet.org

Received: 16 March 2021 Accepted: 16 May 2021

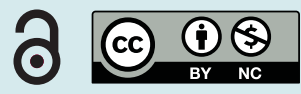

\section{Abstract}

Introduction Bronchoscopic lung volume reduction with endobronchial valves is an important treatment option in selected patients with severe emphysema and absence of collateral ventilation in the treatment target lobe. The Chartis system provides an important physiological assessment of the presence or absence of collateral ventilation. We aimed to evaluate a new feature and determine whether low flow during a Chartis measurement is predictive for the absence of collateral ventilation, and whether this allows for a procedure to be shortened by earlier terminating the Chartis measurement. This is measured with the "volume trend for the previous $20 \mathrm{~s}$ " (VT20).

Methods We retrospectively evaluated 249 Chartis assessments of patients scheduled for bronchoscopic lung volume reduction procedures. The VT20 was calculated, and several thresholds were compared between patients with collateral ventilation (CV positive) and without collateral ventilation (CV negative).

Results $100 \%$ of the CV negative patients reached a threshold of VT20 $\leqslant 6 \mathrm{~mL}$, whereas all CV positive patients reached a VT2 $\geqslant 7 \mathrm{~mL}$. The median "time saved" between VT20 $=6 \mathrm{~mL}$ and end of assessment was $60 \mathrm{~s}$ (range $5-354 \mathrm{~s}$ ).

Conclusion The threshold of VT20 $\leqslant 6 \mathrm{~mL}$ is a reliable method to exclude the presence of collateral ventilation when air flow rates are low and can therefore reduce bronchoscopic lung volume procedure times.

\section{Introduction}

Bronchoscopic lung volume reduction (BLVR) with endobronchial valves is an effective treatment for patients with severe emphysema and hyperinflation [1-4]. One of the key factors for response is the absence of collateral ventilation between the treatment target lobe and the ipsilateral lobe(s) [2, 3, 5-7].

The presence or absence of collateral ventilation can be predicted based on the fissure completeness between lobes [7, 8]. However, a more accurate assessment can be performed using the Chartis Pulmonary Assessment System (Pulmonx Inc., Redwood City, CA, USA), which provides a physiological assessment of airflow through the target lobe [5,9]. The Chartis system consists of a catheter with a balloon at the distal tip, designed to be inserted into the airways through the working channel of a bronchoscope. The open lumen at the distal tip of the Chartis catheter can be placed into the target airway, and inflation of the balloon causes the airway to become sealed and isolated. The catheter is connected to the Chartis console that measures the air flow and pressure from the occluded lobe and quantifies the collateral ventilation status $[5,10,11]$.

The Chartis assessment can be performed in patients breathing spontaneously with procedural sedation, or under general anaesthesia. Compared to sedation, Chartis measurement performed under general 
anaesthesia is more feasible with shorter procedure times [12, 13]. Absence of collateral ventilation in patients under general anaesthesia is confirmed if the air flow from the occluded lobe reaches zero, with an immediate return of airway flow after deflating and removing the balloon catheter $[6,13]$. In many cases, there may be an evident reduction of flow, suggesting absence of collateral ventilation; however, because of the very low flow rate, it can take a significant amount of time for the flow rate to reach "zero" [10].

During some Chartis assessments, the momentary appearance of sudden spikes in the flow rate can confound the assessment. Integration of the flow rate over a fixed period of time during this situation can attenuate this artefact. Therefore, the Chartis software (version 6.0.5) has been updated to continually measure and display the total expired volume over the last $20 \mathrm{~s}$ : the "volume trend for the previous $20 \mathrm{~s}$ " (VT20).

With this feature, the expired volume in the last $20 \mathrm{~s}$ is measured, and this is shown continuously on the Chartis console, next to the currently used flow curve (figure 1). The VT20 value is shown after the first $20 \mathrm{~s}$ of the Chartis assessment.

The present study aimed to validate whether there is a threshold of the VT20 which is predictive for the absence of collateral ventilation in situations where the flow rate during a Chartis measurement is low, and potentially shortening the Chartis procedure by earlier termination of the Chartis measurement. For this, we measured and continuously monitored VT20 based on the hypothesis that if a low flow is predictive of the absence of collateral ventilation, it would lead to shorter procedure time. This results in an easier procedure, with less manipulation of the airway wall by the Chartis balloon and catheter.

\section{Methods}

\section{Study design and population}

This is a single-centre retrospective study conducted at the University Medical Center Groningen, the Netherlands. Anonymised Chartis assessments previously performed in a routine clinical care setting were analysed. Patients with severe emphysema and hyperinflation who were eligible for valve treatment and were scheduled for Chartis assessment as part of regular care in the Bronchoscopic Emphysema Treatment in the Netherlands registry (BREATHE-NL) were included. All patients provided informed consent regarding their treatment and use of their data for future scientific purposes (BREATHE-NL registry; ClinicalTrials.gov Identifier: NCT02815683).

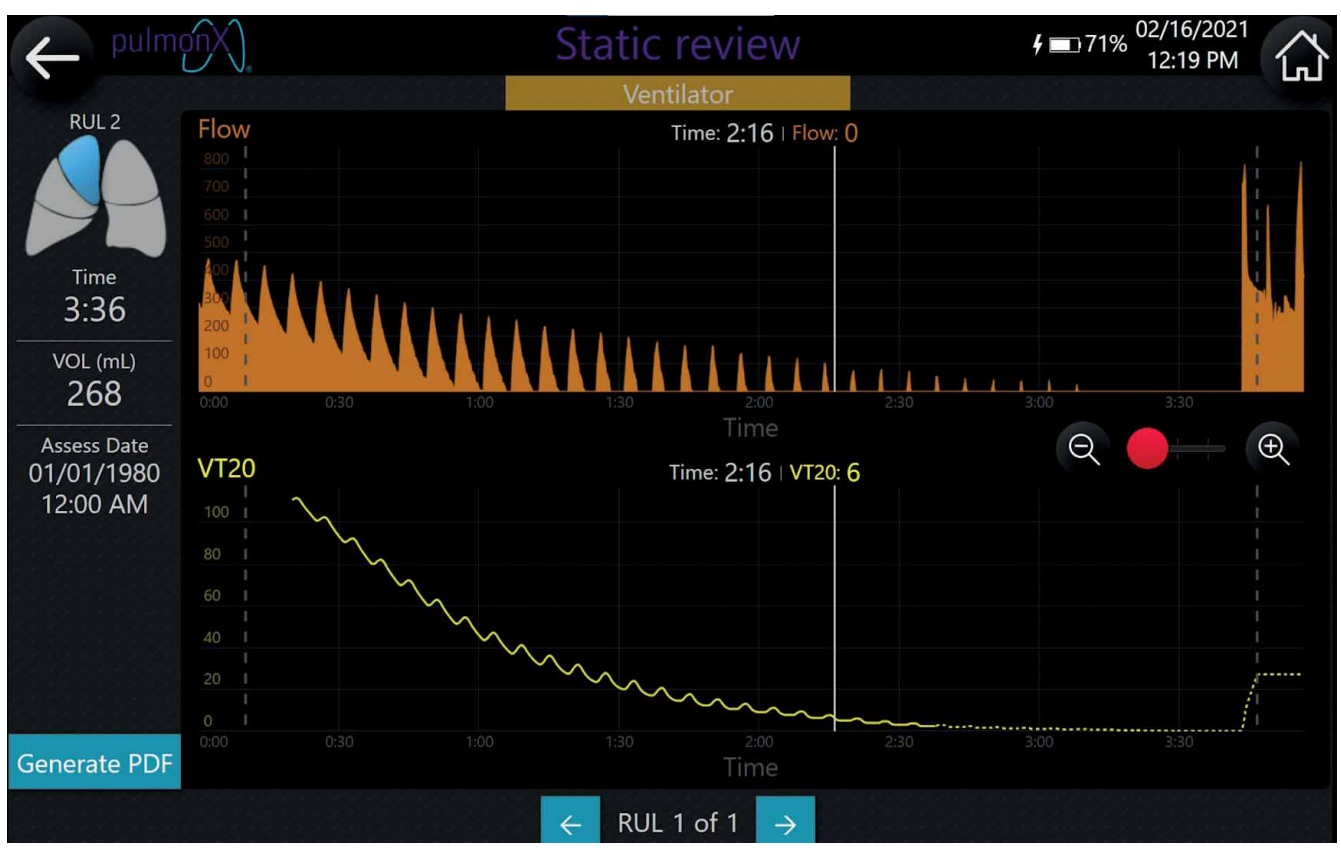

FIGURE 1 Chartis measurement screen image showing the actual flow and the "volume trend for the previous $20 \mathrm{~s}$ " (VT20) plotted for a collateral ventilation (CV) negative patient phenotype in the right upper lobe. This assessment reached $\mathrm{VT} 20=6 \mathrm{~mL}$ at the $2 \mathrm{~min} 16 \mathrm{~s}$ mark, whereas the total measurement was $3 \mathrm{~min} 36 \mathrm{~s}$. 


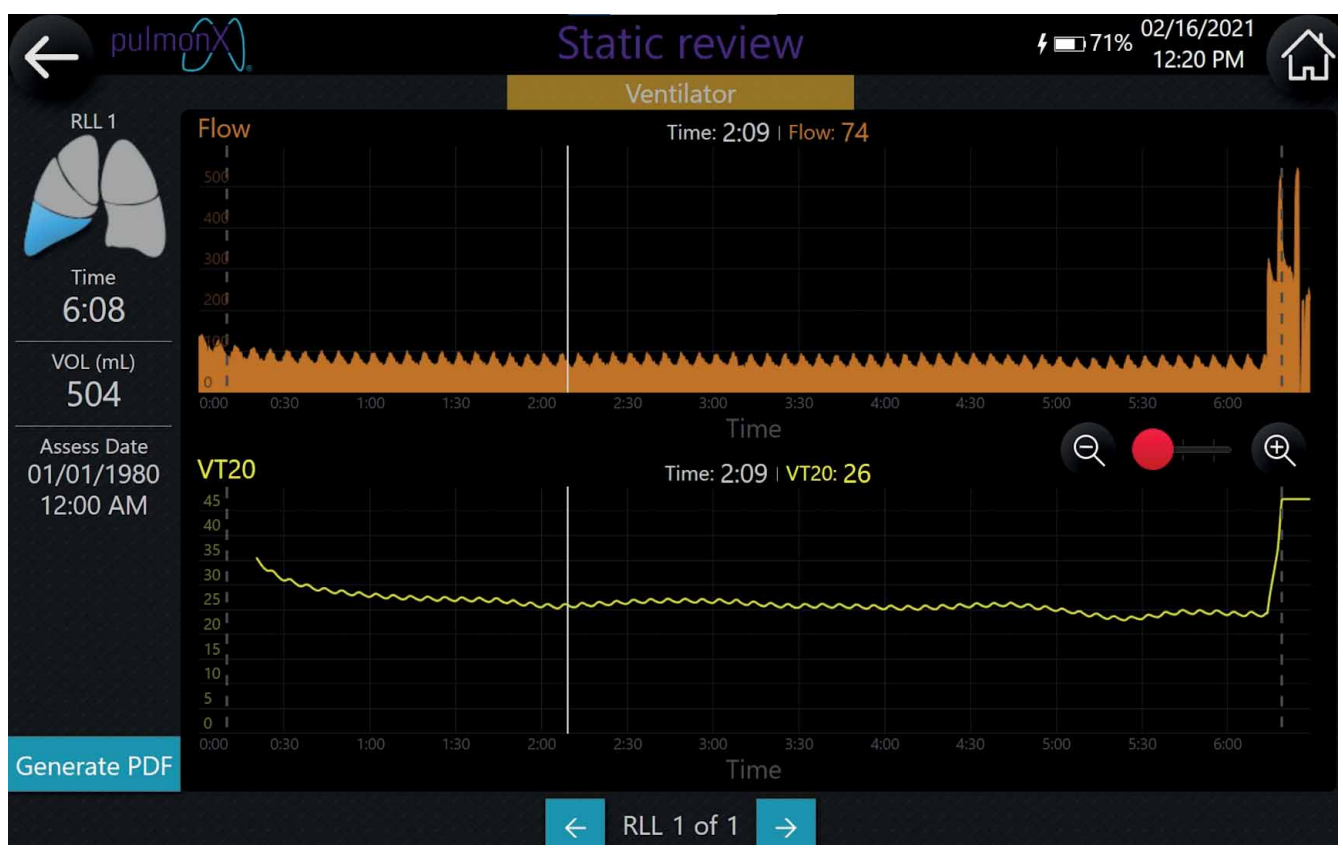

FIGURE 2 Chartis measurement screen image showing the actual flow and the "volume trend for the previous $20 \mathrm{~s}$ " (VT20) plotted for a collateral ventilation (CV) positive patient phenotype. This assessment never reaches a VT20 value below VT20=23 mL.

\section{Chartis measurements}

All Chartis assessments included in the analysis were performed under general anaesthesia with patients intubated with a flexible 9-mm endotracheal tube. Positive pressure ventilation was applied in all patients as per routine practice, with low ventilation frequency (8-10 times per minute), with an inspiratory/ expiratory ratio of 1:3 to 1:4 and preferably a positive end-expiratory pressure of $3 \mathrm{cmH}_{2} \mathrm{O}[10,13]$.

Collateral ventilation over the fissure of the target lobe was measured and scored as presence of collateral ventilation (CV positive), absence of collateral ventilation (CV negative) or inconclusive. In some patients, multiple measurements were performed in several lobes, e.g. when there was more than one treatment target.

\section{Chartis VT20 measurements}

The original raw output data of the Chartis assessments performed during bronchoscopy were used to evaluate the effectiveness of the new VT20 feature on the Chartis 6.0.5 software. An example of a CV negative and a CV positive Chartis assessment is shown in figures 1 and 2, respectively.

The selection of Chartis assessments for inclusion in the analysis was based on the algorithm shown in table 1, to indicate whether an assessment was valid or inconclusive. The valid Chartis assessments were evaluated to determine whether the VT20 data were valid or invalid. For VT20 data to be valid, there

\section{TABLE 1 Selection criteria for valid Chartis measurements to calculate the optimal VT20 threshold}

1. Presence of positive flow prior to start of assessment.

2. The flow should be consistent.

- This flow may be decreasing over the course of the assessment, but there should be no extended duration of missing flow. This indicates proper catheter balloon positioning and sealing of the airways and that the catheter has not been clogged.

- There should be no sudden increases in flow to a much higher level. This could indicate that the catheter balloon seal was lost.

- During the assessment, if there is an instantaneous loss or drop in flow within the first $30 \mathrm{~s}$ and flow does not resume, the assessment should be abandoned and a new one should be re-initiated.

3. At the end of the assessment, the total volume of air exhaled by the patient during the assessment should have been $>50 \mathrm{~mL}$. 
should be presence of air flow at the end of the assessment (in CV positive patients) or the presence of air flow when the VT20 reached a value of $6 \mathrm{~mL}$ and below so that the VT20 could reasonably be used to indicate the end of an assessment. The time of the end of the assessment was recorded. The lowest VT20 value was recorded in all assessments and for CV negative assessments, the time point at which the VT20 was $6 \mathrm{~mL}, 5 \mathrm{~mL}, 4 \mathrm{~mL}, 3 \mathrm{~mL}, 2 \mathrm{~mL}, 1 \mathrm{~mL}$ or $0 \mathrm{~mL}$.

\section{Statistical analysis}

To compare outcomes between the CV negative and CV positive groups, we used an independent-samples $t$-test in case of normal distribution and a Mann-Whitney $U$ test in case of non-normal distribution, p-values below 0.05 were considered statistically significant and mean or median data were calculated per group. All statistical analyses were performed using SPSS version 22 (IBM, New York, NY, USA).

Results

A total of 279 Chartis assessments were evaluated. Thirty assessments were excluded because the VT20 values were invalid to use, as described in the Methods section. Ultimately, 249 Chartis assessments were analysed (187 CV negative and $62 \mathrm{CV}$ positive).

\section{VT20}

Of the $187 \mathrm{CV}$ negative patients, $100 \%$ reached a minimum value of VT20 $\leqslant 6 \mathrm{~mL}$ during the last 2 minutes of assessment. Additionally, 98.9\% reached a value of VT $20 \leqslant 3 \mathrm{~mL}$ and $90.4 \%$ a VT20 $\leqslant 1 \mathrm{~mL}$. Of the $62 \mathrm{CV}$ positive patients, $100 \%$ did not reach a VT20 $\leqslant 6 \mathrm{~mL}$, and the lowest VT20 was $7 \mathrm{~mL}$. The distribution is shown in figure 3.

Time assessment

The median time of the Chartis measurements was $240 \mathrm{~s}$ (range 77-864) in all patients. In CV positive patients the median time was $304 \mathrm{~s}$ (range 122-533) and in CV negative patients, $226 \mathrm{~s}$ (range 77-864) $(\mathrm{p}=0.021)$ (see table 2).

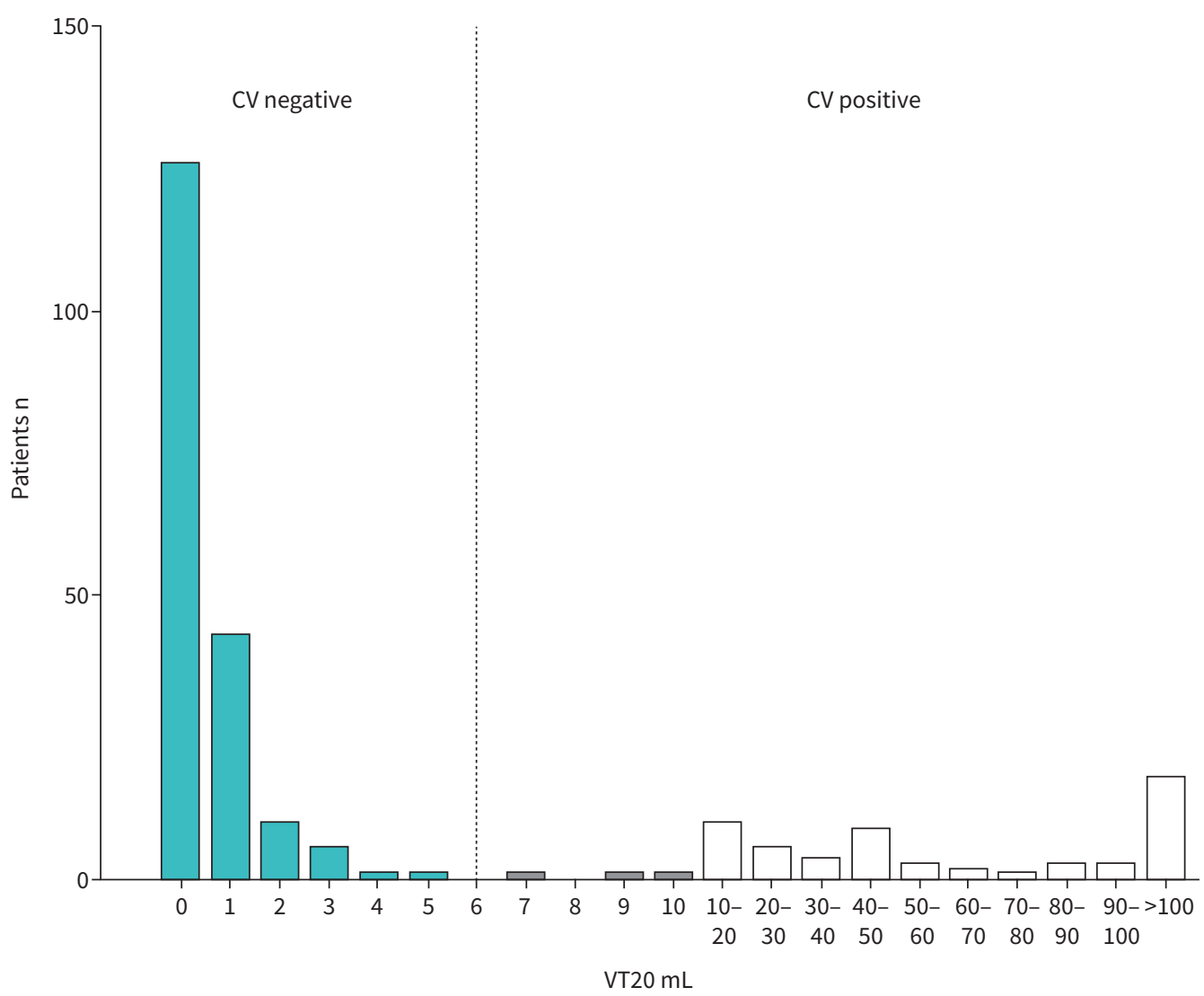

FIGURE 3 Distribution of minimum "volume trend for the previous $20 \mathrm{~s}$ " (VT20) values in collateral ventilation (CV) negative and CV positive measurements. 
TABLE 2 Results of Chartis assessment: duration of measurement and expiratory volume during measurement

\begin{tabular}{|c|c|c|c|c|}
\hline & Total & CV negative & CV positive & p-value \\
\hline Subjects $\mathrm{n}$ & & 249 & 187 & 62 \\
\hline \multicolumn{5}{|l|}{ Duration of Chartis assessment } \\
\hline Total time, s & $240(77-864)$ & $226(77-864)$ & $304(122-533)$ & 0.021 \\
\hline Time to VT20 $=6 \mathrm{~mL}, \mathrm{~s}$ & & $168(36-546)$ & & \\
\hline Difference, s & & $60(5-354)$ & & \\
\hline \multicolumn{5}{|c|}{ Expiratory volume during Chartis assessment } \\
\hline Expiratory volume, $\mathrm{mL}$ & $320(15-1780)$ & $240(15-983)$ & $1014(115-1780)$ & $p<0.005$ \\
\hline Expiratory volume at VT20 $=6 \mathrm{~mL}, \mathrm{~mL}$ & & $235(11-991)$ & & \\
\hline Difference, $\mathrm{mL}$ & & $5(0-120)$ & & \\
\hline
\end{tabular}

The median time to VT20=6 mL was $168 \mathrm{~s}$ (range 36-546). The median time difference between the end of measurement and the VT20=6 mL time point ("time saved") was $60 \mathrm{~s}$ (range 5 to 354), as shown in figure 4.

\section{Volume}

The median measured expiratory volume was $320 \mathrm{~mL}$ (range 15-1780) in all patients (table 2). In CV negative patients this was $240 \mathrm{~mL}$ (range 15-983), compared to $1014 \mathrm{~mL}$ (range 115-1780) in CV positive patients $(\mathrm{p}<0.005)$. The median difference between the total expired volume and the expired volume in $\mathrm{CV}$ negative patients at VT20 $=6 \mathrm{~mL}$ was $5 \mathrm{~mL}$ (range $0-120$ ).

\section{Discussion}

Multiple clinical trials have demonstrated the benefits of BLVR with one-way endobronchial valves in patients with severe emphysema who have little to no collateral ventilation in the target lobe [1-4]. The assessment of collateral ventilation status (presence or absence of collateral ventilation) is crucial in determining the eligibility of a patient for valve treatment for BLVR. The Chartis system provides a physiological assessment of airway under simulated conditions of valve placement in the target lobe to confirm the presence or absence of collateral ventilation $[5,7,9,13]$. It is important to get a valid Chartis

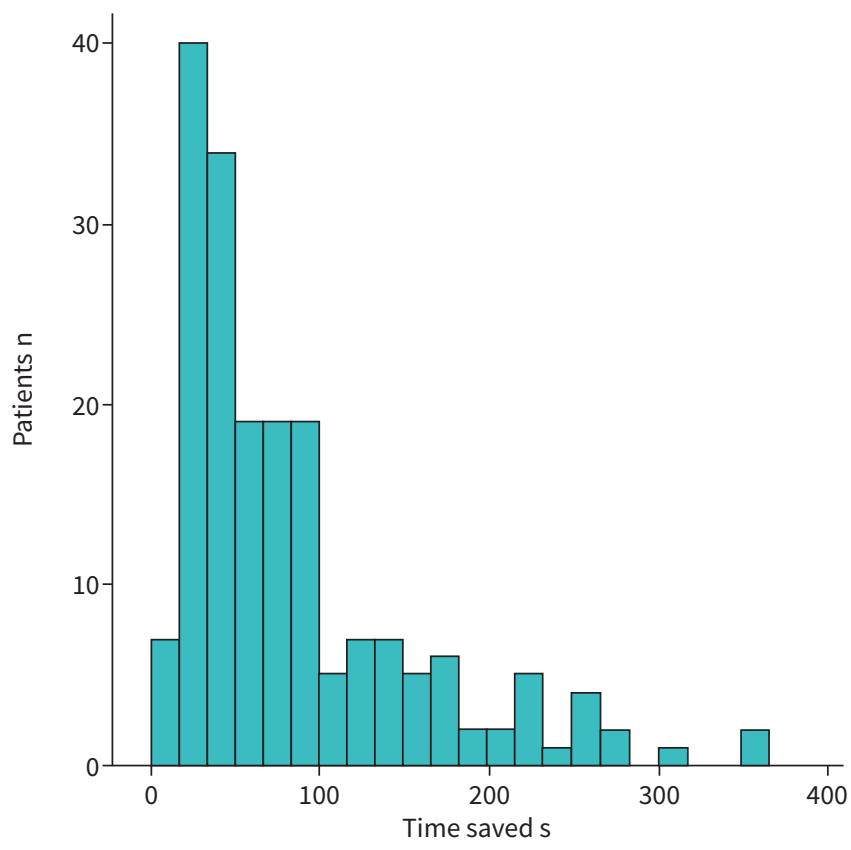

FIGURE 4 Distribution of "time saved" between "volume trend for the previous $20 \mathrm{~s}$ " (VT20)=6 mL and total measurement in collateral ventilation (CV) negative patients. 
assessment, but sometimes the measurement can be challenging [10, 14, 15]. For example, if there is no flow due to obstruction of the Chartis catheter with mucus plugs or contact of the distal tip with the mucosa, or a no-flow pattern of the lower lobes, this can be interpreted falsely as absence of collateral ventilation [14-16]. Furthermore, Chartis assessments can show a low flow pattern, and it can take a long time before the flow actually reaches "zero" [14].

In order to reduce the Chartis assessment time in cases where very low air flow persists for a longer period of time, the VT20 measure that integrates the flow for the last $20 \mathrm{~s}$ has been incorporated into the Chartis software. We evaluated the effectiveness of the new VT20 feature through a review of $187 \mathrm{CV}$ negative and $62 \mathrm{CV}$ positive Chartis assessments.

This analysis shows that when the VT20 value was $\leqslant 6 \mathrm{~mL}$, all patients are CV negative. Therefore, if this threshold is achieved, an assessment can be terminated before the air flow actually reaches zero while still being confident that there is no collateral ventilation. This may shorten the Chartis assessment time by minutes and will significantly shorten the total procedure time. As a result, there is less manipulation of the airways, and this may facilitate an easier valve-treatment procedure.

Although this is a retrospective study, the previously obtained Chartis measurements were re-analysed prospectively using the raw output data and run again with the new software feature and hence reflect the actual measurements. The VT20 feature may not be applicable in all Chartis assessments, especially if the procedure is challenging. It is important that there is a continuous flow during the Chartis measurement to use the VT20 cut-off value. Therefore, the assessment should be evaluated critically during the procedure, and if the measurement does not fulfil the criteria described in the methods section, the VT20 value should not be used.

A limitation of this study is that the VT20 assessments analysed included only Chartis measurements performed under general anaesthesia with standard ventilator settings. As such, these results cannot be extrapolated to measurements in patients under conscious sedation and spontaneous breathing. Although this may yield comparable results, there is no positive pressure ventilation and the methods of measurement differ. Therefore, the cut-off value of VT $20 \leqslant 6 \mathrm{~mL}$ should only be used in Chartis measurements in patients under general anaesthesia.

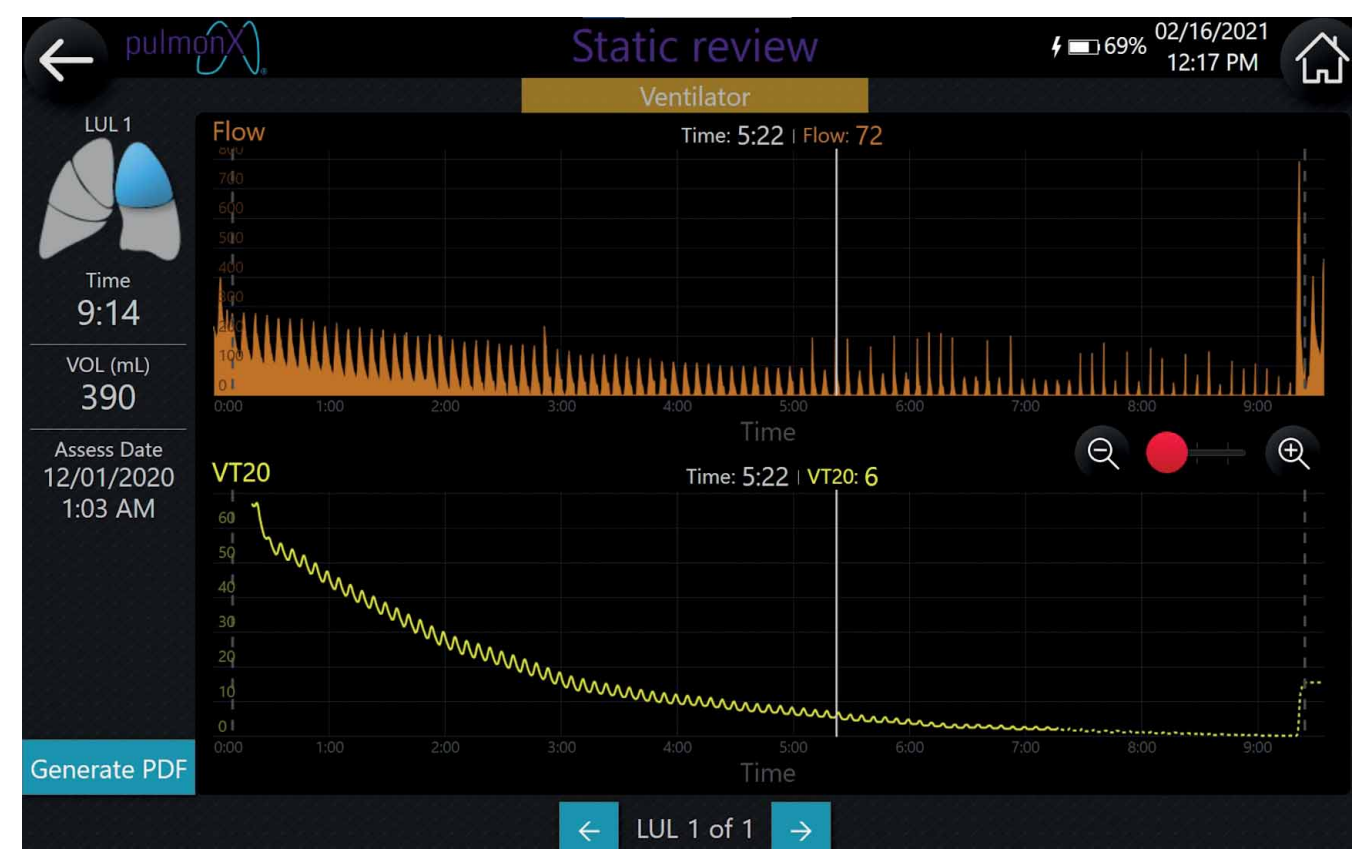

FIGURE 5 Chartis measurement output image showing the "volume trend for the previous $20 \mathrm{~s}$ " (VT20) value plotted for an assessment with continued high spikes in air flow (flow of $72 \mathrm{~mL} \cdot \mathrm{min}^{-1}$ at $5: 22 \mathrm{~min}$ ) values for the duration of the assessment. These spikes cause confounding peak flow trend values, while the VT20 is a good indicator of the continued decline in the amount of total exhaled volume. The VT20 is $6 \mathrm{~mL}$ at 5:22 min, whereas the total measurement was 9:14 min (difference: $232 \mathrm{~s}$ ). 
Herzog et al. [17] have previously shown the additional value of adding a diagnostic algorithm including the expiratory flow, resistance and expired volume in patients measured under spontaneous breathing to shorten the measurement time.

There may be variations in ventilator settings between patients and between hospitals. This could impact the utility of the cut-off of $6 \mathrm{~mL}$ in the last $20 \mathrm{~s}$. Nevertheless, if standard settings are used as described, a measurement of the total volume integrated for the last $20 \mathrm{~s}$ is valuable in avoiding confusion resulting from the spikes in flow patterns that some patients may exhibit. The probable cause for this pattern is the release of very low amounts of volume from the targeted lobe, maybe due to airway collapse. Nevertheless, this leads to small spikes in flow, and this pattern usually results in a longer measurement time, as it takes more time for the flow to reach "zero", even though the total flow is very low (figure 5).

In conclusion, we found that the VT20 threshold of $6 \mathrm{~mL}$ or less during Chartis assessments provides a valuable and reliable method to identify the absence of collateral ventilation while reducing procedure time. This may lead to less manipulation of the airways and less anaesthesia time and facilitates the endobronchial valve treatment procedure.

Conflict of interest: T.D. Koster has nothing to disclose. K. Klooster has nothing to disclose. H. McNamara is an employee of Pulmonx and Pulmonx has provided their salary and granted stock options as part of their compensation. N.S. Shargill is a full time employee of Pulmonx Corporation and owns stock and has stock options in Pulmonx. S. Radhakrishnan is a full time employee of Pulmonx Corporation and has stock or stock options in the company. R. Olivera is an employee of Pulmonx and Pulmonx has provided their salary and granted stock options as part of their compensation. As an employee of Pulmonx, R. Olivera has patents planned, issued, and pending with Pulmonx. D-J. Slebos reports PulmonX Corp, USA collaborated on the software tool used in this study (no financial involvement). Outside the submitted work, D-J. Slebos is a principal investigator for PulmonX Corp, USA, and has received consulting fees from and participated on a Data Safety Monitoring Board or Advisory Board for PumonX Corp, USA.

\section{References}

1 Kemp SV, Slebos DJ, Kirk A, et al. A multicenter randomized controlled trial of zephyr endobronchial valve treatment in heterogeneous emphysema (TRANSFORM). Am J Respir Crit Care Med 2017; 196: 1535-1543.

2 Klooster $\mathrm{K}$, ten Hacken $\mathrm{NH}$, Hartman JE, et al. Endobronchial valves for emphysema without interlobar collateral ventilation. N Engl J Med 2015; 373: 2325-2335.

3 Criner GJ, Sue R, Wright S, et al. A multicenter randomized controlled trial of zephyr endobronchial valve treatment in heterogeneous emphysema (LIBERATE). Am J Respir Crit Care Med 2018; 198: 1151-1164.

4 Valipour A, Slebos DJ, Herth F, et al. Endobronchial valve therapy in patients with homogeneous emphysema. Results from the IMPACT Study. Am J Respir Crit Care Med 2016; 194: 1073-1082.

5 Herth FJ, Eberhardt R, Gompelmann D, et al. Radiological and clinical outcomes of using Chartis to plan endobronchial valve treatment. Eur Respir J 2013; 41: 302-308.

6 Slebos DJ, Shah PL, Herth FJ, et al. Endobronchial valves for endoscopic lung volume reduction: best practice recommendations from expert panel on endoscopic lung volume reduction. Respiration 2017; 93 : 138-150.

7 Klooster K, Koster TD, Ruwwe-Glosenkamp C, et al. An integrative approach of the fissure completeness score and Chartis assessment in endobronchial valve treatment for emphysema. Int $\mathrm{J}$ Chron Obstruct Pulmon Dis 2020; 15: 1325-1334.

8 Koster TD, van Rikxoort EM, Huebner RH, et al. Predicting lung volume reduction after endobronchial valve therapy is maximized using a combination of diagnostic tools. Respiration 2016; 92: 150-157.

9 Klooster K, Slebos DJ. Endobronchial valves for the treatment of advanced emphysema. Chest 2021; 159: 1833-1842.

10 Herth FJF, Slebos DJ, Criner GJ, et al. Endoscopic lung volume reduction: an expert panel recommendation update 2017. Respiration 2017; 94: 380-388.

11 Herth FJF, Slebos DJ, Criner GJ, et al. Endoscopic lung volume reduction: an expert panel recommendation update 2019. Respiration 2019; 97: 548-557.

12 Welling JBA, Hartman JE, Ten Hacken NHT, et al. Chartis measurement of collateral ventilation: conscious sedation versus general anesthesia - a retrospective comparison. Respiration 2018; 96: 480-487.

13 Welling JBA, Klooster $\mathrm{K}$, Hartman JE, et al. Collateral ventilation measurement using Chartis: procedural sedation vs general anesthesia. Chest 2019; 156: 984-990.

14 Gesierich W, Samitas K, Reichenberger F, et al. Collapse phenomenon during Chartis collateral ventilation assessment. Eur Respir J 2016; 47: 1657-1667. 
15 Welling JBA, Koster TD, Hartman JE, et al. Temporary right middle lobe occlusion with a blocking device to enable collateral ventilation measurement of the right major fissure. Respiration 2020; 99: 516-520.

16 Koster TD, Klooster K, Ten Hacken NHT, et al. Endobronchial valve therapy for severe emphysema: an overview of valve-related complications and its management. Expert Rev Respir Med 2020; 14: 1235-1247.

17 Herzog D, Thomsen C, Poellinger A, et al. Outcomes of endobronchial valve treatment based on the precise criteria of an endobronchial catheter for detection of collateral ventilation under spontaneous breathing. Respiration 2016; 91: 69-78. 